\title{
Orthostatic stability with intravenous levodopa
}

Shan H Siddiqi, Mary L Creech, Kevin J Black

Intravenous levodopa has been used in a multitude of research studies due to its more predictable pharmacokinetics compared to the oral form, which is used frequently as a treatment for Parkinson's disease (PD). Levodopa is the precursor for dopamine, and intravenous dopamine would strongly affect vascular tone, but peripheral decarboxylase inhibitors are intended to block such effects. Pulse and blood pressure, with orthostatic changes, were recorded before and after intravenous levodopa or placebo---after oral carbidopa---in 13 adults with a chronic tic disorder and 16 tic-free adult control subjects. Levodopa caused no statistically or clinically significant changes in blood pressure or pulse. These data add to previous data that support the safety of i.v. levodopa when given with adequate peripheral inhibition of DOPA decarboxylase. 


\title{
Orthostatic stability with intravenous levodopa
}

\author{
Shan H. Siddiqi, M.D. (1), \\ Mary L. Creech, R.N., M.S.W., L.C.S.W. (2), \\ Kevin J. Black, M.D. (1-4)* ORCID 0000-0002-6921-9567 \\ Departments of (1) Psychiatry, (2) Neurology, (3) Radiology, and (4) Anatomy \& \\ Neurobiology, and Division of Biology and Biomedical Sciences, Washington University School \\ of Medicine, St. Louis, Missouri, USA \\ * Address correspondence to Dr. Black at Campus Box 8134, 660 S. Euclid Ave., St. Louis, \\ Missouri, USA or kevin@WUSTL.ed
}




\section{Abstract}

Intravenous levodopa has been used in a multitude of research studies due to its more predictable pharmacokinetics compared to the oral form, which is used frequently as a treatment for Parkinson's disease (PD). Levodopa is the precursor for dopamine, and intravenous dopamine would strongly affect vascular tone, but peripheral decarboxylase inhibitors are intended to block such effects. Pulse and blood pressure, with orthostatic changes, were recorded before and after intravenous levodopa or placebo - after oral carbidopa - in 13 adults with a chronic tic disorder and 16 tic-free adult control subjects. Levodopa caused no statistically or clinically significant changes in blood pressure or pulse. These data add to previous data that support the safety of i.v. levodopa when given with adequate peripheral inhibition of DOPA decarboxylase.

Copyright (C) 2015, the authors

\section{Keywords}

levodopa, intravenous, carbidopa, randomized controlled trial, blood pressure, heart rate, Tourette syndrome

\section{Introduction}

The first therapeutic use of levodopa for Parkinson disease (PD) was by the intravenous route (Birkmayer and Hornykiewicz, 1961, 1998; Hornykiewicz, 2010).). Oral administration is preferred clinically due to ease of use, although intravenous (i.v.) levodopa infusion has been favored in certain clinical circumstances (Chase et al., 1994; Abramsky and Goldschmidt, 1974; Horai et al., 2002; Mizuno et al., 2009).

The i.v. route has advantages for some research purposes as well (Black et al., 2004, 2010, 2015;). However, levodopa is approved by the U.S. Food and Drug Administration for treatment of PD and other parkinsonian conditions only in a tablet formulation. In the U.S., giving an approved drug by another route for research purposes may require an investigational new drug (IND) application if changing the route of administration "significantly increases the risks (or decreases the acceptability of the risks)" (\$21 CFR 312.2(b)(iii)). Some have assumed that this might hold for i.v. compared to oral levodopa.

In fact, however, numerous studies have reported on brief ( $<24 \mathrm{hr})$ infusions or large singledose i.v. boluses, and i.v. levodopa has been tolerated approximately as well as oral levodopa (Abraham et al., 2015; Siddiqi et al., 2015). One study even deliberately attempted to induce hallucinations by giving high-dose i.v. levodopa to patients at high risk, but produced no hallucinations (Goetz et al., 1998). However, data on hemodynamic effects of i.v. levodopa have been limited over the past 20 years, and such results have not yet been quantitatively reported in the presence of a peripheral decarboxylase inhibitor (Abraham et al., 2015; Siddiqi et al., 2015).

Here we provide quantitative data, from a double-blind, random-allocation crossover study, on orthostatic blood pressure and pulse responses to i.v. levodopa in the presence of adequate carbidopa pretreatment. 


\section{Methods}

\subsection{Subjects}

44 generally healthy adults (23 with Tourette syndrome or chronic motor tic disorder [TS] and 21 tic-free healthy control $[\mathrm{HC}]$ subjects) enrolled in a study investigating dopaminergic effects on cortical function during a working memory task as measured by functional magnetic resonance imaging (ClinicalTrials.gov identifier NCT00634556). The study was approved by the Human Research Protection Office (IRB) of Washington University in St. Louis (project \#050832, \#201105100), and all subjects provided written documentation of informed consent prior to participation. This study was performed under FDA IND \#69,745, Kevin J. Black, SponsorInvestigator. After the first 10 subjects had been enrolled, the FDA asked us to record orthostatic blood pressure and pulse before and during the infusions. No subjects took any dopaminergic or antidopaminergic medications at baseline, including levodopa, dopamine agonists, or antipsychotics. Six subjects dropped out or were withdrawn from the imaging study (claustrophobia 1, abnormal structural MRI 1, scheduling problems 2, vomiting 2). Complete vital signs were still available for one of the two subjects who were excluded from the imaging study due to vomiting, so these data were included. Therefore, 15 of the 44 subjects were not included in vital signs analysis (10 subjects enrolled before initiation of vital sign collection, 5 subjects dropped out before full range of vital signs could be collected), leaving 29 subjects for analysis.

\subsection{Medications}

No subjects were taking dopaminergic or antidopaminergic medications at baseline. All subjects avoided caffeine, nicotine, and proteins starting at midnight before the morning of the study. Water, juice, and other non-protein food items were allowed prior to study initiation, but subjects had no oral intake during the study period. At least 1 hour after taking $200 \mathrm{mg}$ carbidopa by mouth, levodopa was given intravenously in a $2 \mathrm{mg} / \mathrm{mL}$ solution according to the "final protocol" described in Black et al. (2003). Specifically, a loading dose of $0.6426 \mathrm{mg} / \mathrm{kg}$ was given i.v. over 10 minutes followed by a maintenance infusion at $2.882 \times 10^{-5} \mathrm{mg} / \mathrm{kg} / \mathrm{min} \times(140$ $\mathrm{yr}-\mathrm{age} / \mathrm{yr}$ for an additional $90 \mathrm{~min}$. A 35-year-old patient weighing $70 \mathrm{~kg}$ would receive a total dose of $64 \mathrm{mg}$ (in $32 \mathrm{~mL}$ of normal saline); an oral dose of 150-200 mg would provide the same total absorbed dose, though over a slower time scale (Sasahara et al 1980; Robertson et al., 1989; Kompoliti et al., 2002).). The mean peak levodopa plasma concentration $\left(C_{p}\right)$ with this method was $\sim 2350 \mathrm{ng} / \mathrm{ml}$, and the steady-state $C_{p}$ was $\sim 600 \mathrm{ng} / \mathrm{ml}$ (Black et al., 2003). On a separate day at least 1 week later, each patient received a placebo infusion after carbidopa. The order of the levodopa and placebo infusions was balanced. Both placebo and levodopa infusions were initiated between 8:00 AM and 10:00 AM on the study day. Study staff were blinded to the order of infusions, so both infusions occurred at approximately the same time of day.

\subsection{Measurements}

Vital signs were measured for each patient before and after the infusion on each day. Each vital sign measurement included heart rate, systolic blood pressure, and diastolic blood pressure $(\mathrm{P}$, SBP, DBP) measured when the subject had lain supine for at least 5 minutes, and repeated after at least 1 minute standing, a protocol that was approved by the FDA reviewer. The method of blood pressure measurement was consistent between pre-infusion and post-infusion 
measurements: most measurements were taken electronically, but measurements by manual sphygmomanometry were conducted on a minority of study days. At the end of the study, these measurements were available on both infusion days for 29 patients. Subjects and staff measuring vital signs were blind to infusion order.

After each infusion, subjects completed the Pittsburgh Side Effects Rating Scale (Pelham et al., 1993), a self-rated checklist of common psychotropic side effects in which scores range between 0 and 57. Before and after each infusion, subjects completed a visual analog scale (on a scale of 1-100) to rate light-headedness-dizziness, nausea-vomiting, sleepiness, and overall health.

\subsection{Statistical analysis}

Means for each vital sign parameter were compared between levodopa treatment days and placebo treatment days by paired t tests. For each parameter, within-subjects confidence intervals were computed based on patients for whom the parameter was available for both placebo and levodopa days (Morey, 2008). Pittsburgh Side Effects Rating Scale scores and change in visual analog scale scores for adverse effects were compared similarly.

\section{Results}

14 patients received placebo infusion on the first study day and levodopa on the second day, while 15 received the converse. All data were collected as intended with the exception of a standing pulse for one subject and post-infusion standing blood pressure for one patient after levodopa infusion and for one patient after placebo infusion. Baseline clinical characteristics are summarized in Table 1.

No significant difference was found between vital sign parameters during levodopa versus placebo infusions (table 2, figure 1). Standing increased P and DBP, and the magnitude of this change increased somewhat from earlier to later in the day, but none of these changes differed between levodopa and placebo. The largest absolute orthostatic increases in $\mathrm{P}$, both of which were found on the post-infusion measurements, were $11.7 \mathrm{bpm}$ on the placebo day and $12.3 \mathrm{bpm}$ on the levodopa day. The largest absolute orthostatic increases in DBP, also found on the postinfusion measurements, were $7.4 \mathrm{mmHg}$ in the placebo group and $2.0 \mathrm{mmHg}$ in the levodopa group $(\mathrm{p}=0.20)$. For the differences between levodopa and placebo for all vital sign parameters (supine $\mathrm{P} / \mathrm{SBP} / \mathrm{DBP}$, standing $\mathrm{P} / \mathrm{SBP} / \mathrm{DBP}$, orthostatic change in $\mathrm{P} / \mathrm{SBP} / \mathrm{DBP}$ ), paired $\mathrm{p}$ values ranged between 0.16 (for supine SBP) and 0.92 (for standing SBP). Additionally, no significant difference was found for adverse effect scales (table 3).

\section{Discussion}

These data in generally healthy young adults further support more comprehensive data from previous studies suggesting that i.v. levodopa, at a dose that produces biologically meaningful effects on parkinsonism, does not meaningfully affect orthostatic vital signs when it is given after adequate inhibition of DOPA decarboxylase. Previous studies supporting this conclusion are reviewed elsewhere (Abraham et al., 2015), but here we summarize the key data.

Even before the advent of peripheral decarboxylase inhibitors, large doses of i.v. levodopa were observed to have minimal effects on blood pressure. Moorthy et al. (1972) gave 100-200mg levodopa i.v. over 10 minutes to 8 cardiac patients ages 40-77, and reported slight increase in 
heart rate, aortic and pulmonary arterial pressures, cardiac output, oxygen consumption, heart rate, and systolic and diastolic aortic and pulmonary arterial pressure, along with a slight decrease in systemic arterial resistance; however, specific data and statistical significances were not reported and there was no placebo group. Of note, all of these parameters recovered 30 minutes after infusion and no subjective symptoms were reported, so the authors concluded that intravenous levodopa was safe even in PD patients with advanced cardiovascular disease (Moorthy et al., 1972). Bruno and Brigida (1965) and Baldy-Moulinier et al. (1977) monitored pulse and BP at frequent intervals after i.v. infusions of $2 \mathrm{mg} / \mathrm{kg}(140 \mathrm{mg})$ over 5 minutes and $125 \mathrm{mg}$ in $15 \mathrm{~min}$ respectively, but provided no quantitative data; the authors simply state that there was no change in arterial BP (Baldy-Moulinier et al., 1977, p. 184) or that there were no significant clinical problems with the infusion (Bruno and Brigida, 1965).

The non-neurological side effects of levodopa are further prevented or ameliorated by carbidopa, a peripheral decarboxylase inhibitor whose purpose is to prevent levodopa from being converted to dopamine in the peripheral circulation (Barbeau and Roy, 1976). Peripheral decarboxylase inhibitors revolutionized the treatment of PD 45 years ago (Papavasiliou et al., 1972) by reducing autonomic and gastrointestinal effects of oral levodopa, most commonly doserelated nausea, dizziness or orthostatic hypotension. Smaller doses of peripheral decarboxylase inhibitors (25-50mg of carbidopa) have minimal impact on the autonomic effects of intravenous levodopa (Irwin et al., 1992), but the same occurs with oral levodopa after 50mg of benserazide (Noack et al., 2014), suggesting that the route of administration of leovodopa is not the key difference.

By contrast, here a larger dose of carbidopa $(200 \mathrm{mg}$ ), given early enough that adequate absorption could occur before levodopa administration, effectively prevented any autonomic effects. One might posit that these favorable results are due to the younger sample without Parkinson disease, because hypotension has been observed with levodopa (without PDIs) in several PD studies (Whitsett and Goldberg, 1972). However, hypotension with levodopa in PD is also suppressed by larger doses of PDIs (Mehagnoul-Schipper et al., 2001); similarly, with carbidopa dosed as in the present study oral levodopa produced no mean change in cerebral blood flow (Hershey et al., 1998). Finally, a different brain imaging study in PD that dosed carbidopa similarly found no significant differences in BP or P after $v s$. before i.v. levodopa (Black et al., 2010, and unpublished data). Thus we ascribe the positive results in the present study to the larger and earlier dosing of carbidopa.

Sedation is the most common central side effect of levodopa, and patients with advanced PD also may experience dyskinesias, hallucinations, or confusion. More recently, attention has also been given to gambling, paraphilias, and other disinhibited behavior that emerges in a substantial minority of patients treated with dopamimetics (Black and Friedman, 2006), but these complications are more common with synthetic dopamine agonists and have been reported only after chronic treatment (Weintraub et al., 2010; Poletti et al., 2013). We are unaware of any evidence that central side effects are more common with intravenous levodopa than with oral levodopa.

Overall, these data further elucidate the safety profile of intravenous levodopa and reaffirm that it causes no meaningful change in orthostatic vital signs when combined with oral carbidopa at the dose and schedule used in the present study. This adds to prior data showing an overall safety profile comparable to that of oral levodopa, and may help alleviate some of the regulatory concerns regarding the use of intravenous levodopa in research. 


\section{Acknowledgments}

The authors thank the Tourette Syndrome Association and its Greater Missouri chapter for help with recruitment. Tamara Hershey, Meghan C. Campbell, Elda Shipley, Jonathan Koller, Samantha Ranck, Kathryn Vehe, and Gary Queensen contributed to the overall study from which the data reported here were drawn.

\section{Author contributions}

Study design: KJB

Data collection: KJB, MLC

Data analysis: SHS, KJB

Literature review: SHS, KJB

Writing: SHS, KJB

Review and approve final draft: all authors.

\section{Competing Interests}

No competing interests were disclosed.

\section{References}

N. Abraham, M. Karimi, C. Devine, and K. Black. The human experience with intravenous levodopa. F1000Posters, 6: 268, 2015. URL http://f1000.com/posters/browse/summary/1097795. (Reviewers: See copy uploaded for reviewers.)

O. Abramsky and Z. Goldschmidt. Treatment and prevention of acute hepatic encephalopathy by intravenous levodopa. Surgery, 75: 188-91, Feb 1974.

M. Baldy-Moulinier, P. Bories, H. Michel, and P. Passouant. [Hepatic encephalopathies; hemodynamic and metabolic study of the influence of ammonia and levodopa]. Rev Neurol (Paris), 133: 175-89, 1977.

A. Barbeau and M. Roy. Six-year results of treatment with levodopa plus benzerazide in Parkinson's disease. Neurology, 26: 399-404, May 1976.

W. Birkmayer and O. Hornykiewicz. Der L-3,4-Dioxyphenylalanin (=DOPA)-Effekt bei der Parkinson-Akinese. Wien Klin Wochenschr, 73 (45): 787-788, Nov 1961. [The 1-3,4dioxyphenylalanine (DOPA)-effect in Parkinson-akinesia].

W. Birkmayer and O. Hornykiewicz. The effect of L-3,4-dihydroxyphenylalanine (=DOPA) on akinesia in parkinsonism [reprinted, originally 1961]. Parkinsonism Relat Disord, 4: 59-60, Aug 1998.

K. J. Black and J. H. Friedman. Repetitive and impulsive behaviors in treated Parkinson disease. Neurology, 67: 1118-9, Oct 2006.

K. J. Black, J. L. Carl, J. M. Hartlein, S. L. Warren, T. Hershey, and J. S. Perlmutter. Rapid intravenous loading of levodopa for human research: clinical results. Journal of Neuroscience 
Methods, 127 (1): 19-29, jul 2003. 10.1016/s0165-0270(03)00096-7. URL $\mathrm{http}: / / \mathrm{dx}$. doi.org/10.1016/s0165-0270(03)00096-7.

K. J. Black, T. Hershey, J. M. Hartlein, J. L. Carl, and J. S. Perlmutter. Levodopa challenge neuroimaging of levodopa-related mood fluctuations in Parkinson's disease. Neuropsychopharmacology, 30 (3): 590-601, Dec 2004. 10.1038/sj.npp.1300632. URL http://dx.doi.org/10.1038/sj.npp.1300632.

K. J. Black, J. M. Koller, M. C. Campbell, D. A. Gusnard, and S. I. Bandak. Quantification of Indirect Pathway Inhibition by the Adenosine A2a Antagonist SYN115 in Parkinson Disease. Journal of Neuroscience, 30 (48): 16284-16292, dec 2010. 10.1523/jneurosci.2590-10.2010. URL http://dx.doi.org/10.1523/jneurosci.2590-10.2010.

K. J. Black, M. L. Piccirillo, J. M. Koller, T. Hseih, L. Wang, and M. A. Mintun. Levodopa effects on $\left[{ }^{11} \mathrm{C}\right]$ raclopride binding in the resting human brain $[\mathrm{v} 1$; ref status: indexed, http://f1000r.es/4oe]. F1000Research, 4: 23, jan 2015. 10.12688/f1000research.5672.1. URL http://dx.doi.org/10.12688/f1000research.5672.1.

M. Bouhaddi, F. Vuillier, J. O. Fortrat, S. Cappelle, M. T. Henriet, L. Rumbach, and J. Regnard. Impaired cardiovascular autonomic control in newly and long-term-treated patients with Parkinson's disease: involvement of L-dopa therapy. Auton Neurosci, 116: 30-8, Nov 2004.

A. Bruno and E. Brigida. [Action of L-DOPA on the extrapyramidal symptomatology of haloperidol]. Riv Neurobiol, 11: 646-54, 1965.

D. B. Calne, J. Brennan, A. S. Spiers, and G. M. Stern. Hypotension caused by L-dopa. Br Med J, 1: 474-5, Feb 1970.

T. N. Chase, T. M. Engber, and M. M. Mouradian. Palliative and prophylactic benefits of continuously administered dopaminomimetics in Parkinson's disease. Neurology, 44: S15-8, Jul 1994.

G. C. Cotzias, P. S. Papavasiliou, and R. Gellene. Modification of parkinsonism-Chronic treatment with L-DOPA. New England Journal of Medicine, 280 (7): 337-345, feb 1969. 10.1056/nejm196902132800701. URL http://dx.doi.org/10.1056/NEJM196902132800701.

C. G. Goetz, E. J. Pappert, L. M. Blasucci, G. T. Stebbins, Z. D. Ling, M. V. Nora, and P. M. Carvey. Intravenous levodopa in hallucinating Parkinson's disease patients: high-dose challenge does not precipitate hallucinations. Neurology, 50: 515-7, feb 1998.

T. H. Haapaniemi, M. A. Kallio, J. T. Korpelainen, K. Suominen, U. Tolonen, K. A. Sotaniemi, and V. V. Myllylä. Levodopa, bromocriptine and selegiline modify cardiovascular responses in Parkinson's disease. J Neurol, 247: 868-74, Nov 2000.

T. Hershey, K. J. Black, M. K. Stambuk, J. L. Carl, L. A. McGee-Minnich, and J. S. Perlmutter. Altered thalamic response to levodopa in Parkinson's patients with dopa-induced dyskinesias. Proc Natl Acad Sci U S A, 95: 12016-21, Sep 1998.

T. Horai, T. Nishiyama, H. Yamamoto, and K. Hanaoka. [High dose L-DOPA infusion during general anesthesia for gastrectomy in a patient with parkinsonism]. Masui, 51: 42-5, Jan 2002. 
O. Hornykiewicz. A brief history of levodopa. J Neurol, 257: S249-52, 2010.

R. P. Irwin, J. G. Nutt, W. R. Woodward, and S. T. Gancher. Pharmacodynamics of the hypotensive effect of levodopa in parkinsonian patients. Clin Neuropharmacol, 15: 365-74, Oct 1992.

K. Kompoliti, C. H. Adler, R. Raman, J. H. Pincus, M. T. Leibowitz, J. J. Ferry, L. Blasucci, J. N. Caviness, S. Leurgans, W. M. Chase, L. C. Yones, E. Tan, P. Carvey, and C. G. Goetz. Gender and pramipexole effects on levodopa pharmacokinetics and pharmacodynamics. Neurology, 58: 1418-22, May 2002.

D. J. Mehagnoul-Schipper, R. H. Boerman, W. H. Hoefnagels, and R. W. Jansen. Effect of levodopa on orthostatic and postprandial hypotension in elderly Parkinsonian patients. $J$ Gerontol A Biol Sci Med Sci, 56: M749-55, Dec 2001.

J. Mizuno, S. Kato, M. Watada, and S. Morita. [Perioperative management of a patient with Parkinson's disease with intravenous infusion of levodopa] . Masui, 58: 1286-9, Oct 2009.

S. Moorthy, H. Grendahl, A. Andersen, and C. Müller. The haemodynamic effect of intravenous injection of levodopa. Acta Med Scand, 191: 451-4, may 1972.

R. D. Morey. Confidence intervals from normalized data: A correction to Cousineau (2005). Reason, 4 (2): 61-64, 2008.

C. Noack, C. Schroeder, K. Heusser, and A. Lipp. Cardiovascular effects of levodopa in Parkinson's disease. Parkinsonism Relat Disord, 20: 815-8, Aug 2014.

P. S. Papavasiliou, G. C. Cotzias, S. E. Düby, A. J. Steck, C. Fehling, and M. A. Bell. Levodopa in Parkinsonism: potentiation of central effects with a peripheral inhibitor. $N$ Engl J Med, 286: 814 , jan 1972.

W. E. Pelham, Jr. Pharmacotherapy for children with attention-deficit hyperactivity disorder. School Psychology Review, 22: 199-227, 1993.

M. Poletti, C. Logi, C. Lucetti, P. Del Dotto, F. Baldacci, A. Vergallo, M. Ulivi, S. Del Sarto, G. Rossi, R. Ceravolo, and U. Bonuccelli. A single-center, cross-sectional prevalence study of impulse control disorders in Parkinson disease: association with dopaminergic drugs. J Clin Psychopharmacol, 33: 691-694, Oct 2013. 10.1097/JCP.0b013e3182979830

D. R. Robertson, N. D. Wood, H. Everest, K. Monks, D. G. Waller, A. G. Renwick, and C. F. George. The effect of age on the pharmacokinetics of levodopa administered alone and in the presence of carbidopa. Br J Clin Pharmacol, 28: 61-9, Jul 1989.

K. Sasahara, T. Nitanai, T. Habara, T. Morioka, and E. Nakajima. Dosage form design for improvement of bioavailability of levodopa II: Bioavailability of marketed levodopa preparations in dogs and parkinsonian patients. J Pharm Sci, 69: 261-5, May 1980.

J. M. Sénard, P. Verwaerde, O. Rascol, and J. L. Montastruc. Effects of acute levodopa administration on blood pressure and heart variability in never treated parkinsonians. Hypertens Res, 18 Suppl 1: S175-7, Jun 1995. 
295 S. H. Siddiqi, C. Geiger, N. K. Abraham, M. Karimi, J. S. Perlmutter, and K. J. Black. The 296 human experience with intravenous levodopa. Manuscript submitted for publication, 2015. 297 (Reviewers: See copy uploaded for reviewers.)

298 D. Weintraub, J. Koester, M. N. Potenza, A. D. Siderowf, M. Stacy, V. Voon, J. Whetteckey, 299 G. R. Wunderlich, and A. E. Lang. Impulse control disorders in Parkinson disease: A cross300 sectional study of 3090 patients. Arch Neurol, 67: 589-95, May 2010.

301 T. L. Whitsett and L. I. Goldberg. Effects of levodopa on systolic preejection period, blood 302 pressure, and heart rate during acute and chronic treatment of Parkinson's disease. Circulation, 303 45: 97-106, Jan 1972.

304 J. P. Wolf, M. Bouhaddi, F. Louisy, A. Mikehiev, L. Mourot, S. Cappelle, F. Vuillier, P. Andre, 305 L. Rumbach, and J. Regnard. Side-effects of L-dopa on venous tone in Parkinson's disease: a 306 leg-weighing assessment. Clin Sci (Lond), 110: 369-77, Mar 2006. 
1

Orthostatic vital signs before and after levodopa infusion

No significant changes were observed between IV levodopa or placebo days in (a) heart rate, (b) systolic blood pressure, or (c) diastolic blood pressure. Values shown are mean \pm S.D. for all data. (See Table 2 for means and $95 \%$ confidence intervals from the paired analysis.) 

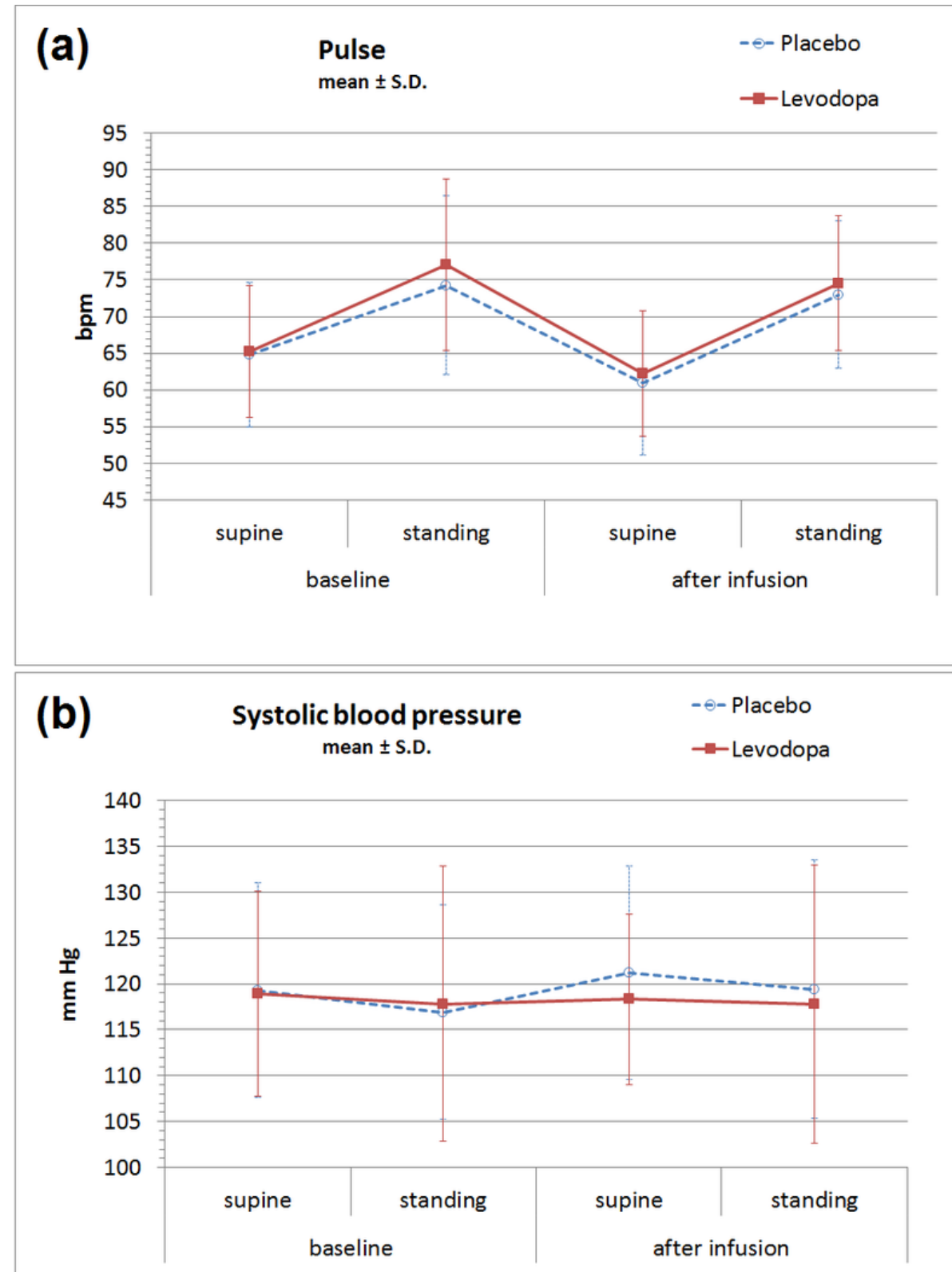

(c)
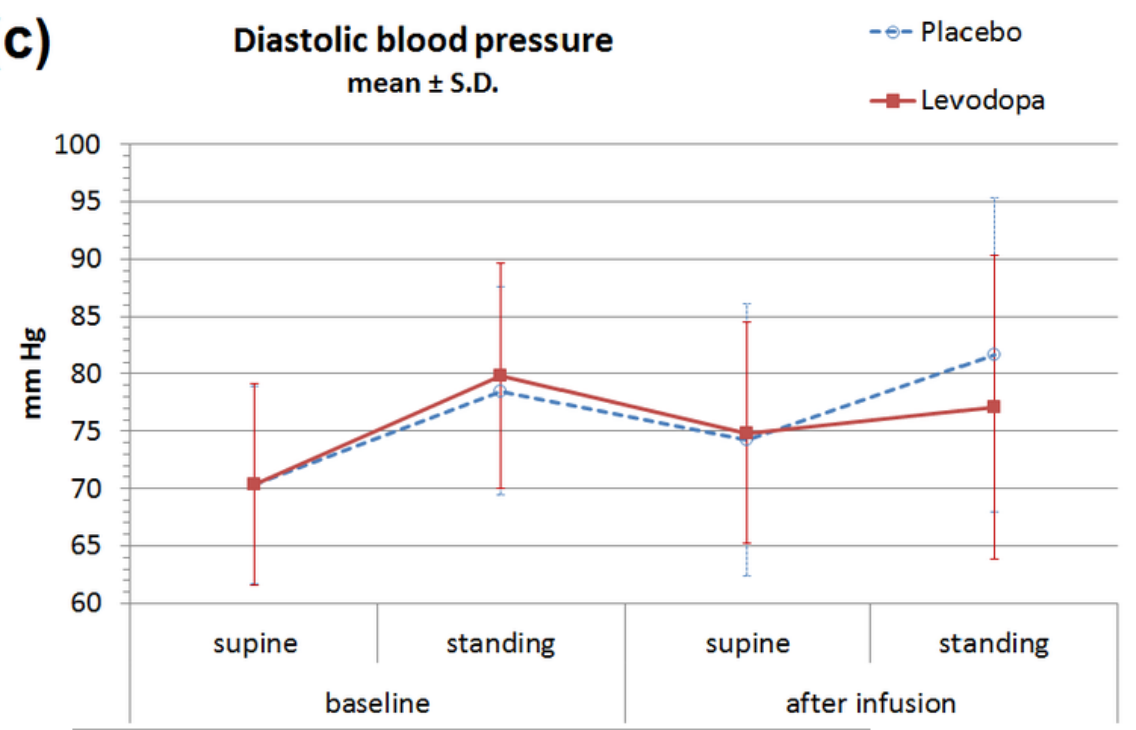

Peer] reviewing PDF | (2015:05:4953:1:1:REVIEW 26 Jul 2015) 


\section{Table $\mathbf{1}$ (on next page)}

Baseline clinical characteristics of subjects

*Of the 3 patients taking antihypertensives, 1 was for hypertension; the other two were taking centrally acting $\alpha_{2}$-adrenergic agonists for treatment of Tourette's syndrome. 


\begin{tabular}{|c|c|}
\hline Age (years) & $32.7 \pm 11.2$ \\
\hline Weight $(\mathrm{kg})$ & $79.1 \pm 12.4$ \\
\hline Sex & $21 \mathrm{M}, 8 \mathrm{~F}$ \\
\hline Concurrent antihypertensives & $10.3 \%^{*}$ \\
\hline Concurrent dopaminergic medications & $0 \%$ \\
\hline
\end{tabular}

1 


\section{Table 2 (on next page)}

Vital sign parameters after levodopa and placebo infusions

Means and $95 \%$ confidence intervals are shown for individual vital sign parameters after levodopa and placebo infusions, for subjects who had data on both days. No significant levodopa-placebo difference was found in any parameter. Units for BP: $\mathrm{mmHg}$; units for P: beats per minute. 


\begin{tabular}{|c|c|c|c|c|}
\hline Condition & Number of pairs & Levodopa $(95 \% \mathrm{CI})$ & Placebo $(95 \% \mathrm{CI})$ & $p$ \\
\hline SBP (supine) & 29 & $118(115,122)$ & $121(118,125)$ & 0.16 \\
\hline SBP (standing) & 27 & $117(112,122)$ & $120(115,125)$ & 0.19 \\
\hline SBP (orthostatic change) & 27 & $-1(-6,4)$ & $-1(-6,4)$ & 0.91 \\
\hline DBP (supine) & 29 & $75(72,78)$ & $74(71,77)$ & 0.86 \\
\hline DBP (standing) & 27 & $77(72,82)$ & $82(77,87)$ & 0.18 \\
\hline DBP (orthostatic change) & 27 & $2(-2,7)$ & $7(2,12)$ & 0.20 \\
\hline P (supine) & 29 & $62(61,64)$ & $61(59,63)$ & 0.34 \\
\hline P (standing) & 28 & $75(72,78)$ & $73(70,76)$ & 0.35 \\
\hline P (orthostatic change) & 28 & $13(10,16)$ & $12(9,15)$ & 0.65 \\
\hline
\end{tabular}


Table 3(on next page)

Self-reported side effects

Mean and 95\% confidence intervals are shown for self-reported side effects with levodopa and placebo infusions. 


\begin{tabular}{|c|c|c|c|}
\hline Parameter & Placebo (95\% CI) & Levodopa $(95 \% \mathrm{CI})$ & $p$ \\
\hline Pittsburgh Side Effects Rating Scale & $2.0(1.2,2.9)$ & $3.0(1.4,3.8)$ & 0.25 \\
\hline Change in VAS (light-headedeness) & $0.0(-2.1,2.1)$ & $3.0(-1.1,7.1)$ & 0.26 \\
\hline Change in VAS (nausea) & $0.7(-0.8,2.3)$ & $-0.2(-3.7,3.4)$ & 0.67 \\
\hline Change in VAS (sleepiness) & $2.8(-3.1,8.6)$ & $4.9(-0.9,10.7)$ & 0.88 \\
\hline Change in VAS (overall health) & $-1.8(-6.2,2.6)$ & $-1.7(-8.6,5.2)$ & 0.88 \\
\hline
\end{tabular}

1 